\title{
Means-end chains and cluster analysis: An integrated approach to improving marketing strategy
}

\author{
RECEIVED: 10 APRIL, 2000 \\ Chin-Feng Lin* and Ming-Yih Yeh \\ *Department of Business Administration, National Chinyi Institute of Technology, 35, \\ Lane 215, Sec. I, Chungshan Road, Taiping Taichung 4II, Taiwan, R.O.C \\ Tel: +886 (0)4 3929845 x 777l; Fax: +886 (0)4 392 9584; \\ e-mail: cflin@chinyi.ncit.edu.tw
}

\begin{abstract}
A new integrated methodology based on cluster analysis is proposed for a more powerful means-end chains (MECs) method. Applying the variables obtained from a survey on the same product (toothpaste), both methods were used to derive the hierarchical value cluster map (HVCM). The new map can handle and develop strategies for pricing, product differentiation, advertising and market segmentation. The purpose of this paper is twofold: to propose improvements for building the HVCM and to understand perceptual orientations and product strategies.
\end{abstract}

\section{INTRODUCTION}

This paper proposes an integrated methodology for developing marketing strategies based on means-end chains (MECs) and cluster methods. MECs are based on a taxonomy of consumer product knowledge involving three key concepts: product attributes, consequences and values. The underlying idea is that product attributes are means for consumers to obtain desired ends, namely values, through the consequences of those attributes. ${ }^{1,2}$ In MEC theory, the key concepts are linked hierarchically in cognitive structures; that is, a product's attributes yield particular consequences upon product consumption. These linkages give the analyst critical insights into the values associated with consumer satisfaction.

Traditional MEC analysis involves surveying a large number of consumers about their preferences and consumption habits and using those data to uncover the means-end hierarchies defined by the attributes, consequences and values (A-C-V) and their linkages. Such an analysis leads to a tree diagram, termed a hierarchical value map (HVM), which is by nature structural and represents these linkages. These rich and deep descriptions of knowledge reveal differences between more and less experienced consumers. Thus, marketers can decide which attributes help consumers achieve the values that they want. The HVM is limited, however, in that the most important product attributes cannot be
Chin-Feng Lin is an Associate Professor in the Department of Business

Administration at National Chinyi Institute of Technology, Taiwan. Ming-Yih Yeh is an Associate Professor in the Department of Business

Administration at National Taiwan University of Science and Technology. 
determined, because we cannot use it to compute the percentage of consumers for whom a given attribute is linked, to a critical value.

A method that integrates MECs and the right statistical methods could solve the problem of determining these percentages by identifying the respondents associated with each A-C-V linkage. Such a method would allow the marketer to determine the relative importance of product attributes in achieving the values associated with consumer satisfaction. This expanded MEC methodology would be a powerful tool for developing highly targeted marketing strategies.

This paper presents a new MEC/cluster analysis methodology that allows the marketer to compute the percentage of respondents associated with a given $\mathrm{A}-\mathrm{C}-\mathrm{V}$ line in a straightforward fashion. This improved method is the basis for three new maps. The first two, the hierarchical value cluster map (HVCM) and the positive hierarchical value cluster map (PHVCM), are closely related. They state explicitly which and how many survey respondents are associated with each $\mathrm{A}-\mathrm{C}-\mathrm{V}$ line in the HVM. The third map is the linkage breakdown map (LBM), an expanded version of the HVM that displays critical statistical data with the HVM tree. The purpose of this paper is to provide insights into building these maps and to propose a new methodology for developing and understanding related product strategies based on the information contained in them.

\section{LITERATURE REVIEW}

In the marketing literature, the predominant approach to analysing perceived self-relevance is MEC analysis. ${ }^{3-9}$ MEC analysis assumes that a reasonable aggregated chain can be constructed given data from a set of respondents, even if the set includes individual respondents who are able to articulate only some of the steps in a chain. ${ }^{10}$ MECs provide a theoretically elaborate conceptualisation of the abstraction of consumers' product knowledge. ${ }^{11}$ Figure 1 shows the MEC model, which has three levels of abstraction (attributes, consequences and values), each divided into two categories.

At the lowest level are attributes, which can be concrete attributes relatively tangible product characteristics such as product size or colour or abstract attributes such as product style or quality, which are further removed from the physical characteristics and tend to subsume multiple concrete attributes. At a higher level of abstraction are consequences, which can be the functional consequences (often tangible) of product use, such as losing weight or saving money, or psychological/social consequences, such as feeling good or attracting attention. Finally, at the highest levels of abstraction, consumers can represent a product in terms of the values and basic needs that are achieved through its use, such as self-esteem or happiness. ${ }^{12,13}$

The MEC model links a product's attributes to the consequences for 
Figure 1: Means-end chain consumer product knowledge taxonomy

\begin{tabular}{|c|c|c|c|c|c|}
\hline \multicolumn{2}{|c|}{ Attributes } & \multicolumn{2}{|c|}{ Consequences } & \multicolumn{2}{|c|}{ Values } \\
\hline Concrete & Abstract & Functional & Psychosocial & Instrumental & Termina \\
\hline Attributes & Attributes & Consequences & Consequences & Values & Values \\
\hline
\end{tabular}

consumers of using the product and to the personal values they place on its use, which determine whether the consequences are desirable or undesirable. $^{14}$ In other words, MEC analysis interprets these product-consumer relationships in terms of the terminal 'value' that constitutes the 'core' sense of self. ${ }^{15,16}$ Data are gathered for an MEC analysis by interviewing consumers singly and in depth, and asking them to state which concepts are most important for them in differentiating among the types or brands of a given product. The A-C-V linkages are elicited from the consumers through a laddering technique, leading to the development of a hierarchical value map (HVM). ${ }^{17} \mathrm{Lad}-$ dering consists of a series of directed probes based on mentioned distinctions initially obtained from perceived differences among specific brands of products or services. Again, after the initial distinction obtained by contrasting brands is elicited, all subsequent higher-level elements are not brand specific. ${ }^{18-20}$ The laddering results can be used to create an HVM summarising all interviews across consumers, which represents dominant perceptual orientations, or 'ways of thinking', with respect to the product or service category. $^{21-23}$

An HVM, which graphically represents a set of MECs, can be thought of as an aggregate cognitive structure map. Statistical graphics, graphical perception theory and the semiology of graphics have all been explored in an effort to improve the design of the HVM such that it better represents the original data in a clear and simple fashion. ${ }^{24}$ Researchers have used graph theory and correspondence analysis to improve the building of the HVM and enhance its function in an example involving wine cooler data. ${ }^{26}$

Several researchers have emphasised the difference between the 'macro' and 'micro' perspectives. ${ }^{27-30}$ The micro approach focuses on the linkages between existing attributes of a product, the consequences for the consumer of the attributes, and the values placed by the consumer on the 
consequences. The macro perspective, by contrast, develops a classification system for segmenting individuals into qualitative groups defined by value orientations. Several research firms have developed lifestyle classification systems. The most widely used is SRI Consulting's Values and Lifestyles (VALS 2) typology. ${ }^{31-33}$ VALS is a psychographic system which links demographics and purchase patterns with psychological attitudes through cluster analysis.

Cluster analysis, the key statistical method in the VALS system, is also the chosen method for the present research. It allows the analyst to define meaningful subgroups of individuals or objects. ${ }^{34}$ The goal is to classify a sample of entities (individuals or objects) into a small number of mutually exclusive groups based on similarities and differences in the data. In cluster analysis, the groups are not predefined; instead, the technique is used to identify the groups.

By using cluster analysis, our new integrated MEC method will fulfil the requirements of both macro and micro analysis. Given additional data on each respondent (demographic information in addition to consumption habits), our method will be useful for macro analysis, since it will allow the marketer to develop a detailed demographic profile of the respondents associated with each $\mathrm{A}-\mathrm{C}-\mathrm{V}$ line. It will also be useful for micro analysis since it will present an explicit and detailed view of the $\mathrm{A}-\mathrm{C}-\mathrm{V}$ linkages (the HVCM).

\section{MEANS-END CHAIN ANALYSIS}

This study is based on 47 valid samples of data collected by interviewing consumers singly and in depth for an MEC analysis of toothpaste. The data are based on five questions designed to determine the following:

- what attributes of toothpaste the consumer prefers when he/she buys it, and why

- what attributes the consumer prefers after usage, and why

- what the consequences of these attributes are for the consumer after usage

- what personal values the consumer can satisfy as a result of the attributes and their consequences.

To list the attributes of toothpaste on the market, the researchers investigated 19 brands of toothpaste. The result was the 17 attributes listed in Table 1, which include 12 obtained through hands-on analysis of each brand and an additional five determined through a literature search. In addition to the attributes, the survey results included 25 consequences and eight values from using toothpaste. Figure 2 shows the HVM obtained using the laddering approach.

\section{CLUSTER ANALYSIS}

The cluster analysis was conducted using data from in-depth interviews based on a structural questionnaire. Completed and usable questionnaires were received from 298 interview 


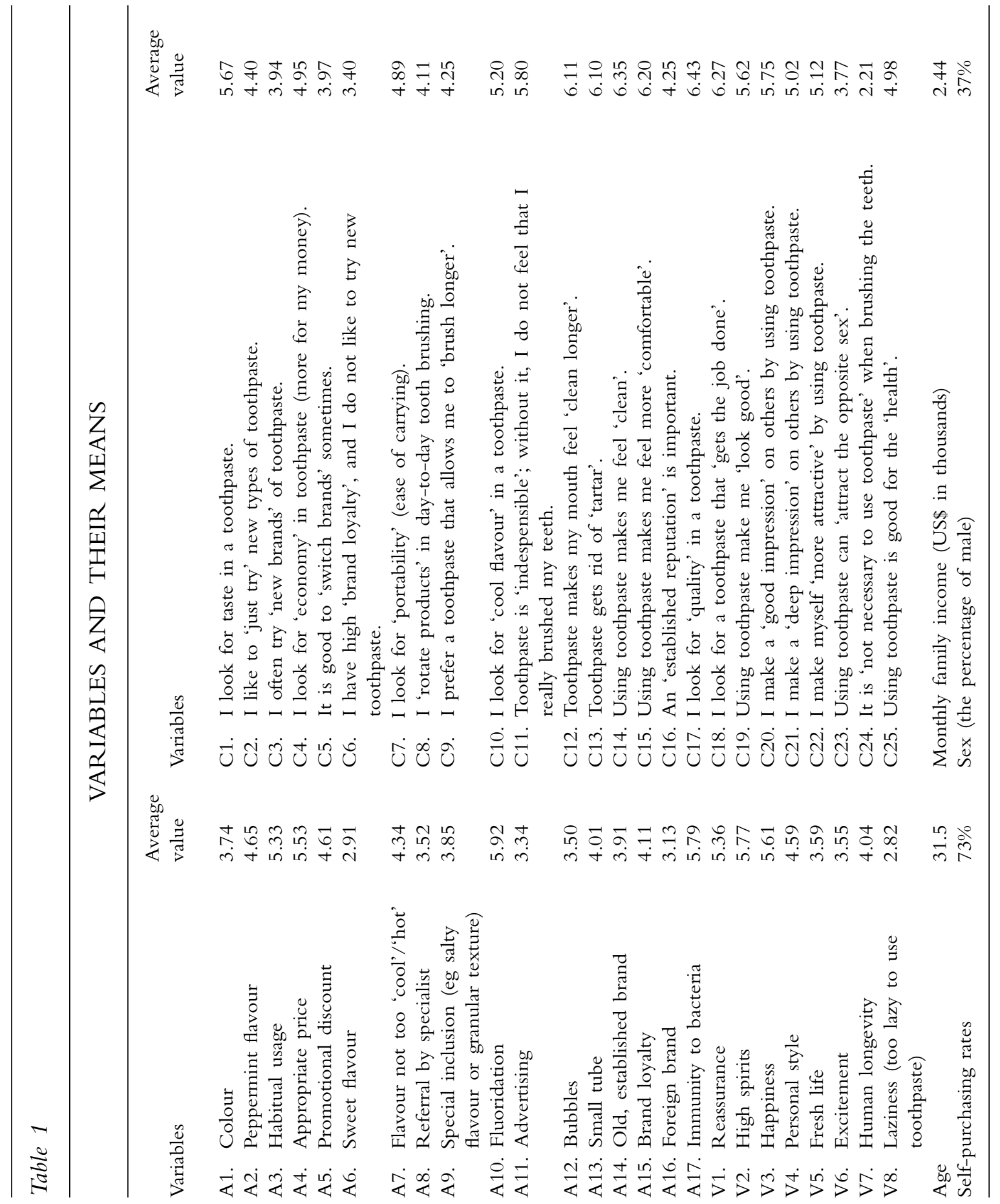

24 Journal of Targeting, Measurement and Analysis for Marketing Vol. 9, I, 20-35 C Henry Stewart Publications 0967-3237 (2000) 
Figure 2: Hierarchical value map for toothpaste

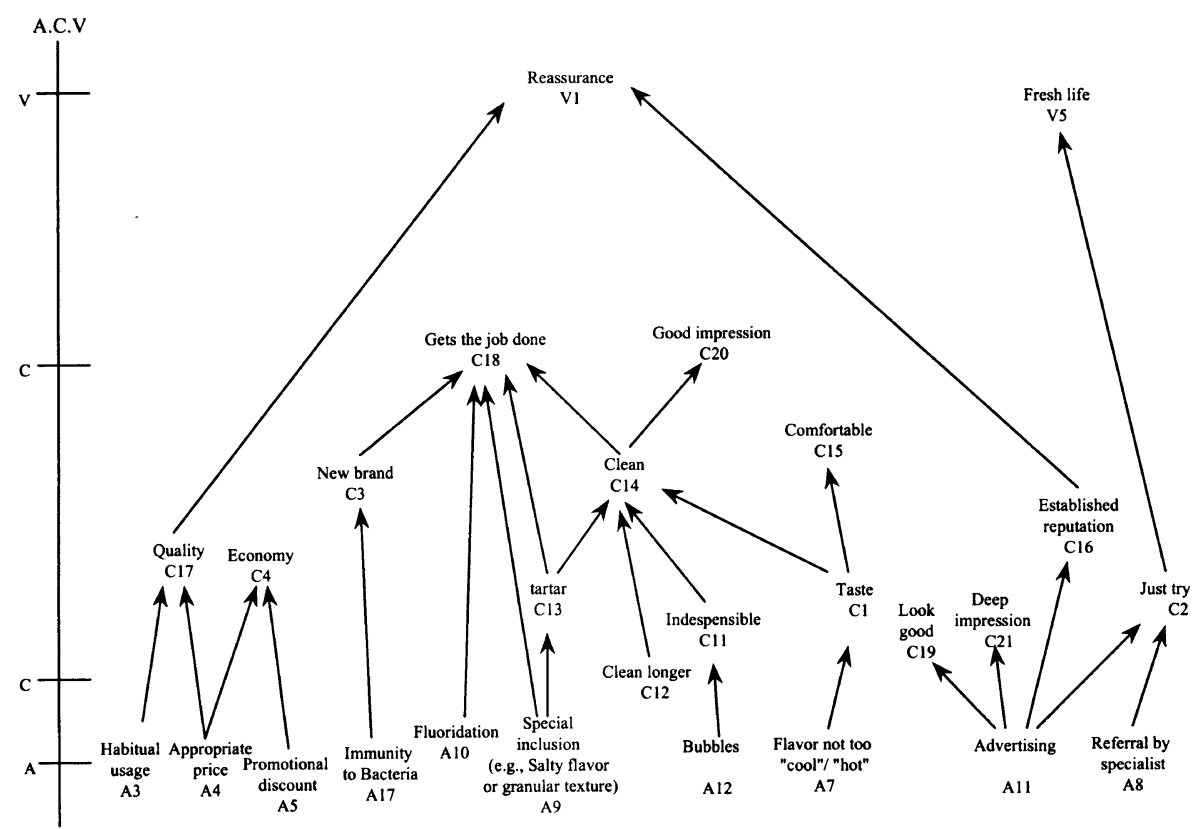

respondents. Excluding 55 samples which had missing values, there were a total of 243 input samples for the cluster analysis. The questions in the questionnaire fell into ten categories. The first three categories concerned the key concepts (attributes, consequences and values), and the other categories concerned the self-purchasing rates, age, sex, occupation, degree of education, monthly family income and region of the respondents. We used the same variables (attributes A1-A17, consequences $\mathrm{C} 1-\mathrm{C} 25$ and value $\mathrm{V} 1-$ V8, scale: $1-7$ on the Likert scale) as in the MEC analysis that generated the HVM of Figure 2.

The cluster analysis in this research was conducted using the K-means of Nonhierarchical Method. There are ten attributes in the HVM (Figure 2), so we limited the cluster analysis to search for ten clusters (range $=65$ ), 11 clusters (range $=54$ ) or 12 clusters (range $=55$ ). Because of the scale of the samples, the cluster analysis resulted in 11 clusters, which we used to analyse marketing strategies. Table 1 lists all the variables with their mean values. The appendix 
Figure 3: Hierarchical value cluster map

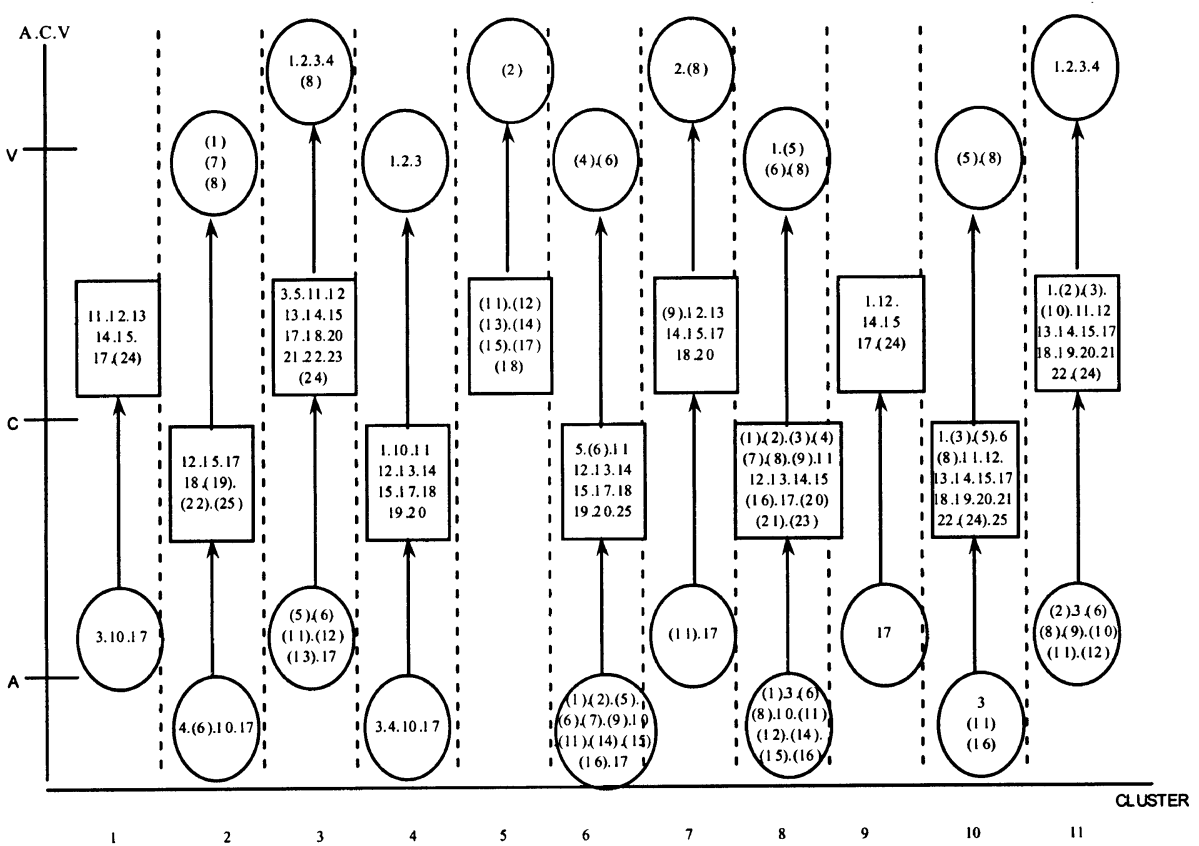

describes each cluster in terms of its size number of respondents in the cluster), demographic profile and A-C$\mathrm{V}$ linkages. If a variable in a given row of the chart appears in parentheses, it is unimportant for its cluster. Other variables in the row are important, and missing variables are deemed ambiguous (not clearly important or unimportant).

There are three possible statuses for each $\mathrm{A}, \mathrm{C}$ and $\mathrm{V}$ variable in the cluster analysis: 'important', 'unimportant' and 'ambiguous'. The variables are labelled important or unimportant using the following rules:
$-\mathrm{C}_{\mathrm{av}} \leqq 2$; the variable is unimportant

$-\mathrm{C}_{\mathrm{av}} \geqq 6$; the variable is important

$-\mathrm{S}_{\mathrm{av}}-\mathrm{C}_{\mathrm{av}} \geqq 2$; the variable is unimportant

$-\mathrm{C}_{\mathrm{av}}-\mathrm{S}_{\mathrm{av}} \geqq 2$; the variable is impor$\operatorname{tant}$

where

$$
\begin{aligned}
\mathrm{C}_{\mathrm{av}}= & \text { average value of variables in } \\
& \text { each cluster } \\
\mathrm{S}_{\mathrm{av}}= & \begin{array}{l}
\text { average value of variables in all } \\
\text { samples. }
\end{array}
\end{aligned}
$$

The default status of a variable not labelled (un)important is ambiguous. 
Figure 4: Positive hierarchical value cluster map

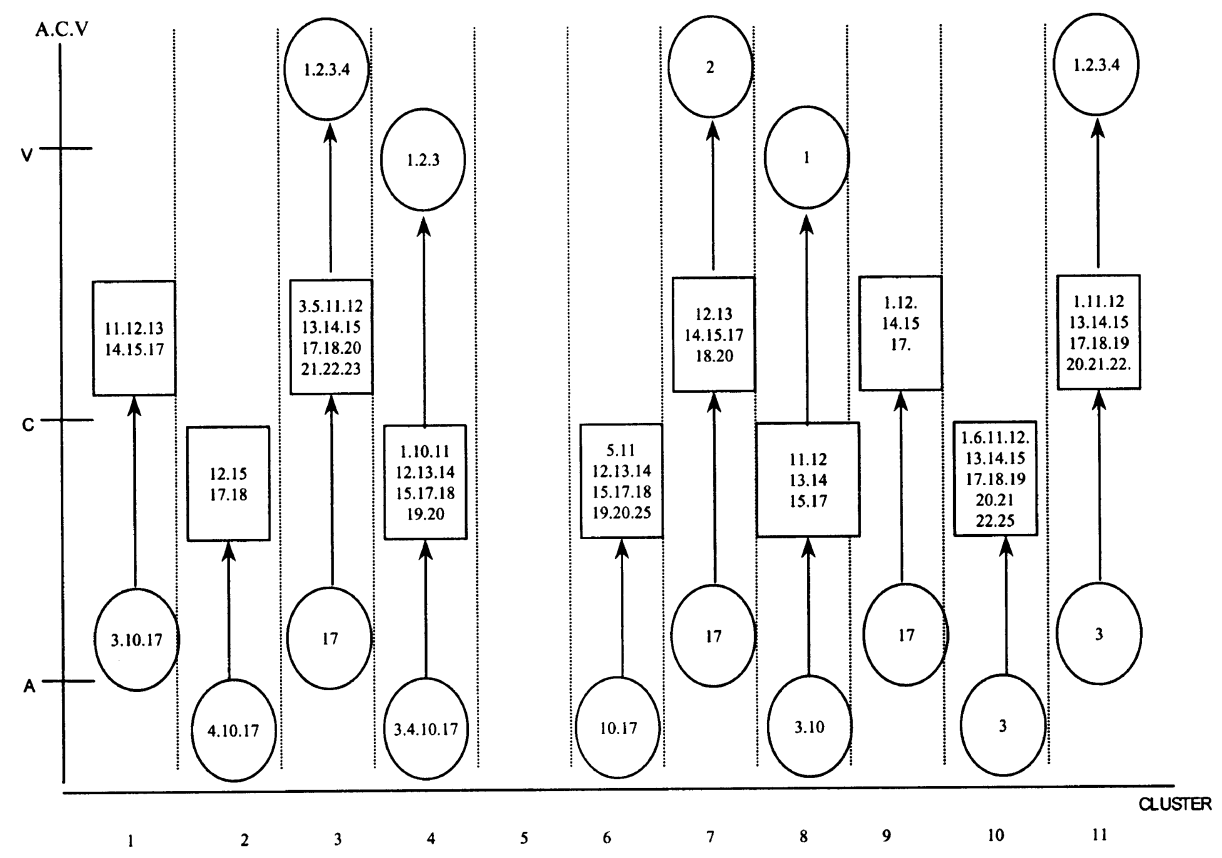

Figures 3 and 4 show the hierarchical value cluster map (HVCM) and the positive hierarchical value cluster map (PHVCM), two closely related maps we developed for a concise display of the information in the HVM and the appendix. Each set of A-C-V linkages listed for a given cluster in these maps suggests one or more possible marketing strategies. The suggestive power of the HVCM and PHVCM demonstrates why it is so important to understand which/how many consumers translate a product's attributes into meaningful associations among the attributes, consequences and values. By enumerating these linkages, our integrated MEC/cluster analysis method lays out strategy alternatives for enterprises trying to achieve a marketing objective. Clearly, the new diagrams offer more revealing insights into marketing strategies than the HVM alone. Thus, our method integrating MECs and cluster analysis can be used to formulate more detailed marketing strategies than traditional MEC analysis. 


\section{DISCUSSION}

In the debate on the relative merits of qualitative and quantitative research, researchers believe that qualitative research can lead to an in-depth discussion which uncovers the problems to be solved. In other words, in surveys such as those performed in MEC studies, qualitative research can be used for a more revealing analysis of the data. ${ }^{35}$ Thus, this study adopted the MEC model, which yields the HVM map shown in Figure 2. The HVM map can list and explain the consequences that consumers derive from product attributes and the values that the consequences serve. To strengthen and expand the MEC model, we performed cluster analysis on the MEC output. Manufacturers of toothpaste may follow this integrated methodology to develop more powerful marketing strategies.

\section{Analysis of hierarchical value map}

The highest level of the HVM map shows the perceived value of the product. By observing the consequence/value associations, the marketer can devise potential marketing strategies. For example, 'reassurance' (V1) is associated with 'high quality' (C17), and 'fresh life' (V5) is associated with a 'just try' (C2) approach. Therefore, the marketer could develop the 'advertising' attribute, if he/she wants to achieve the marketing objectives of the corporation. Furthermore, special inclusions (eg salty flavour or granular texture) may satisfy the needs of special groups of consumers, although they serve no practical function. That is, emphasising a special inclusion of a given toothpaste is a good strategy for targeting certain markets.

The HVM structure is based on the assumption that consumers tend to think about a product in terms of its attributes (eg advertising and habit). Thus, in theory, by observing the perceived outcome of different toothpaste attributes, marketers should be able to emphasise the most 'attractive' attributes of the product to win customers and establish consumer loyalty. Figure 2 shows that consumers place importance on five attributes: advertising, function, freshness, price and habitual usage. Our MEC survey revealed, however, that some consumers could not describe the attributes of toothpaste; they were only aware of the consequences of product use. Furthermore, consumers differed in their perceptions of product attributes and the resulting consequences of product use. Moreover, the HVM does not include knowledge of how the attribute/consequence associations are distributed within the consumer population, information that is invaluable for making marketing decisions.

\section{Analysis of hierarchical value cluster map}

The profiles of various clusters in this study are listed in the appendix. The HVCM map (Figure 3) presents the viewpoints of consumers in various clusters. From it, we infer that the 
consumers in clusters 1 and 9 do not associate the attributes of the product with any particular values, and those in cluster 5 do not identify the consequences of toothpaste usage with any particular attributes. The cluster 6 consumers rate several attributes as unimportant, and while they do not associate the 'important' attributes with the two values listed in the HVM, they do associate the attributes with positive consequences. The other clusters all have a complete A-C-V structure. The cluster 3, 4 and 11 consumers agree on several positive consequences and values. Those in clusters $1,3,4,6,7$ and cluster 9 constitute 73.6 per cent of all the surveyed respondents.

By eliminating the unimportant variables of $\mathrm{A}, \mathrm{C}$ and $\mathrm{V}$ in the HVCM map, the PHVCM (Figure 4) was obtained. The data in the PHVCM reveal that 78.9 per cent of the respondents prefer the 'immunity to bacteria' attribute (A17), 47.9 per cent prefer 'habitual usage' attribute (A3) and 44.2 per cent prefer 'fluoridation' attribute (A10). Overall, 40.9 per cent of the respondents had a complete A-C-V structure.

\section{Analysis of linkage breakdown map}

Figure 5 shows the linkage breakdown map (LBM), which augments the HVM tree obtained from traditional MEC analysis with a breakdown of the survey population into A-C-V associations obtained from cluster analysis. The LBM highlights the benefits of the integrated (MEC/cluster analysis) approach. Un- der each attribute, there is a percentage which we obtained by grouping the clusters associated with a given A-C-V linkage and totalling the percentage of respondents in the clusters. The percentages listed for a given attribute are an index (weight) of the attribute's importance, and they are a vital addition to the information obtained through traditional MEC analysis. The HVM states the attribute-consequence-value chains through which marketers can determine which attributes contribute to value satisfaction. In the case of our product (toothpaste), several attributes can be used to reach the consumers' values. Marketers can depend on the attributes percentages displayed in the map (Figure 5) to target and emphasise the most useful attribute. After producing the HVM, HVCM and LBM, the next step is to transform these data into a practical marketing strategy. The integrated method yields the weights (percentages) for each A-C-V linkage defined by the HVM. These weights provide valuable insights into consumer preferences, allowing the marketer to develop workable strategies to achieve the marketing objectives of the corporation.

\section{CONCLUSION}

\section{Applications of MECs}

The HVM emphasises the A-C-V linkages, namely, the personal values and consequent feelings that consumers associate with a product's attributes. Thus, the MEC methodology is a 
Figure 5: Linkage breakdown map

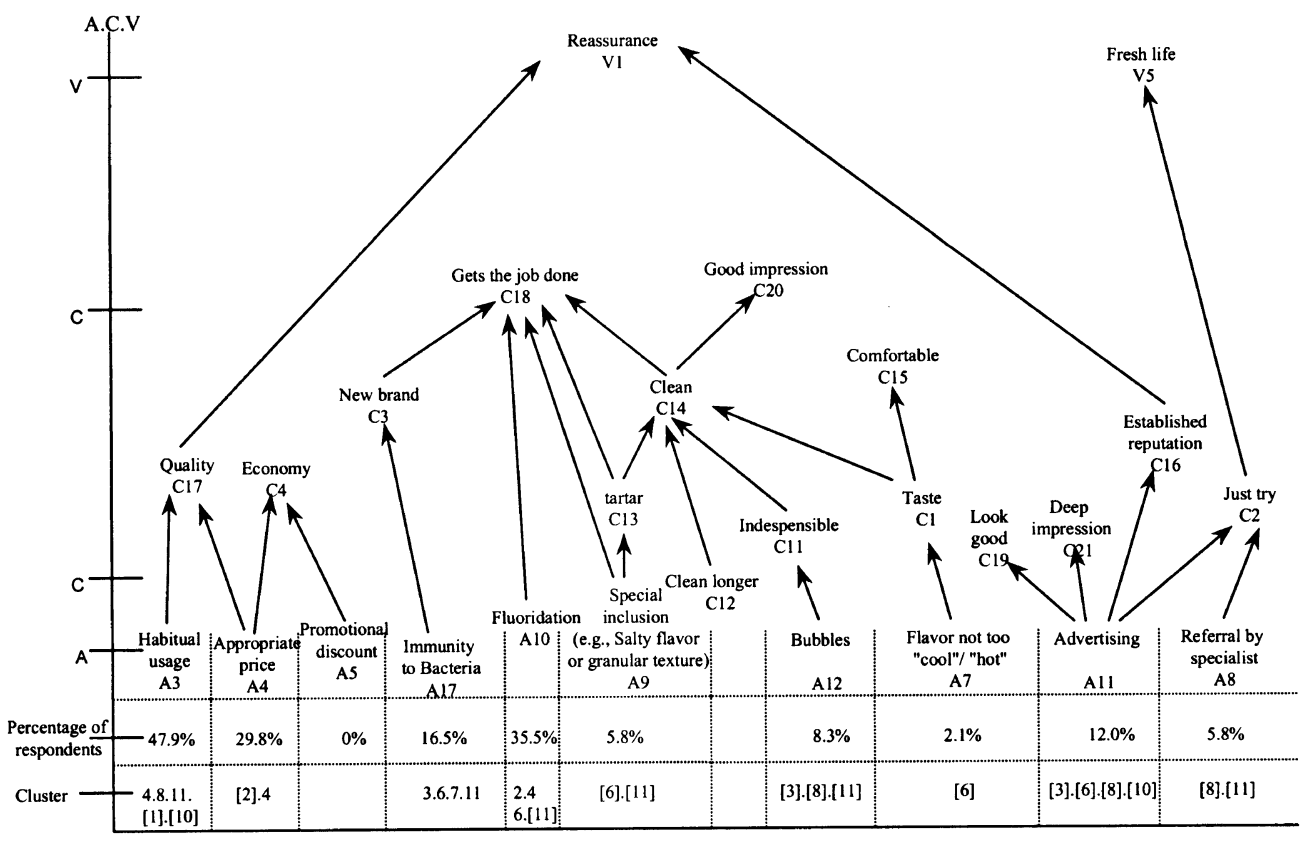

powerful means for targeting the decisive product attributes that will satisfy consumers' expectations and value demands.

\section{Using cluster analysis to enhance the MEC method}

The strengths of our method are reflected in the new HVCM representation which builds on the traditional HVM structure. Cluster analysis in the HVCM is used to explain the demographic characteristics (age, sex, occupation, degree of education, monthly family income and region) of the consumers associated with each
A-C-V linkage. Thus, our method integrates the MECs and cluster analysis to represent explicitly the A-C-V lines (see Figure 3 and Figure 4). With access to the demographic characteristics of the respondents in each cluster, the marketer can more effectively fit the product attributes into segmentation markets.

\section{Comparison of HVM and HVCM}

The traditional MEC method which yields the HVM is a qualitative approach, whereas the integrated method that produces the HVCM is a 
quantitative approach. The survey questions for the two methods are different. Both methods use the same $\mathrm{A}, \mathrm{C}$ and $\mathrm{V}$ variables. After clustering, the HVCM identifies the variables as they appear in the HVM (eg A3 in the HVCM should be identical to A3 as it appears in the HVM). Thus, the HVCM remains comparable with the HVM, but also it enhances the functions of the HVM in marketing strategies. The LBM explicitly states the percentage of consumers associated with each $\mathrm{A}-\mathrm{C}-\mathrm{V}$ line. Marketers can therefore devise strategies that target the demographic characteristics of each cluster. In other words, by understanding the consumer support rates in the PHVCM, the marketer will be able to identify the product attributes favoured in various segmentation markets. That is what marketers look forward to understanding.

\section{Marketing strategy for toothpaste}

\section{Pricing strategy}

In the HVM, the 'appropriate price' attribute (A4) is associated not only with 'economy' (C4) but also with reliable 'quality' (C17). This means that the toothpaste product must adhere to both a 'middling price' and a 'sales promotion' strategy. These dual strategies will satisfy the demands of the consumers' values. Moreover, the 'appropriate price' and 'promotional discount' attributes (A5) are associated with 'economy' and 'reassurance' (V1). The LBM indicates that 24.4 per cent of all respondents attach importance to appropriate price, and of these respondents 66.7 per cent were female.

\section{Product differentiation strategy}

The LBM shows that 31.8 per cent of respondents associate 'gets the job done' (C18) with 'fluoridation' (A10). On the other hand, almost all of the toothpastes in our survey contained fluoride. In other words, it is necessary to differentiate the toothpastes in other ways. For instance, 2.1 per cent of respondents preferred the 'flavour not too cool/hot' attribute (A7), whereas the 'bubbles' and 'special inclusion' attributes (A12 and A9) were not important for 8.3 per cent and 5.8 per cent of respondents, respectively. On the other hand, a far larger percentage of respondents (16.5 per cent) agreed that 'immunity to bacteria' (A17) was an important consideration in buying toothpaste. Therefore, the toothpaste product differentiation strategy must emphasise oral hygiene.

\section{Advertising strategy}

The advertising strategy is very important for toothpaste. This strategy should focus on reassurance (V1) and name recognition (C16). An appropriate marketing strategy should use advertising to take advantage of consumers' impulse to 'just try' (C2) and to promote the brand name. Such a strategy would conform to the A-C-V lines in the LBM.

\section{Market segmentation strategy}

In Figure 5, each cluster is associated with an A-C-V mapping from an end 
value to preferred attribute(s). That is, the consumers in each cluster have definite A-C-V line(s). The appendix explains the demographic characteristics of each cluster. Using the demographic variables to distinguish between customer groups, marketers will know the size of the target market and the media that should be used to reach it efficiently.

The integrated methodology was used to expand the MEC method. The goal of the new integrated method is to transform the HVM data into a practical marketing strategy. In this paper, we illustrated how the method could be used to devise a marketing strategy for an example product (toothpaste). Ultimately, the integrated method can be used to identify decisive attributes for a wide variety of products, giving the marketer invaluable insights for formulating pricing, product differentiation, advertising and market segmentation strategies.

\section{REFERENCES}

1 Gutman, J. (1982) 'A means-end chain model based on consumer categorization processes', Journal of Marketing, Vol. 46, pp. 60-72.

2 Reynolds, T. J. and Olson, J. C. (1998) 'The means-end approach to understanding consumer decision-making: Applications to marketing and advertising strategy', Lawrence Erlbaum Associates, Hillsdale, NJ.

3 Olson, J. and Reynolds, T. (1983) 'Understanding consumers' cognitive structures: Implications for advertising strategy', in Percy, L. and Woodside, A. (eds), 'Advertising and consumer psychology', Lexington Books, Lexington, MA.

4 Gutman, J. (1991) 'Exploring the nature of linkages consequences and values', Journal of Business Research, Vol. 22, pp. 143-148.

5 Walker, B. A. and Olson, J. C. (1991) 'Means-end chains: Connecting products with self', Journal of Business Research, Vol. 22, pp. 111-118.

6 Doucette, W. R. and Wiederholt, J. B. (1992) 'Measuring product meaning for prescribed medication using a meansend chain model', Journal of Health Care Marketing, Vol. 12, pp. 48-54.

7 Thompson, C. J. (1997) 'Interpreting consumers: A hermeneutical framework for deriving marketing insights from the texts of consumers' consumption stories', Journal of Marketing Research, Vol. 34, pp. 438-455.

8 Claeys, C., Swinnen, A. and Abeele, P. V. (1995) 'Consumers' meansend chains for "think" and "feel" products', International Journal of Research in Marketing, Vol. 12, pp. 193-208.

9 Gutman, J. (1997) 'Means-end chains as goal hierarchies', Psychology \& Marketing, Vol. 14, pp. 545-560.

10 Reynolds, T. J. and Gutman, J. (1988) 'Laddering theory, method, analysis, and interpretation', Journal of Advertising Research, Vol. 28, pp. 11-29.

11 Olson and Reynolds (1983) op. cit.

12 Walker, B. A., Celsi, R. and Olson, J. C. (1986) 'Exploring the structural characteristics of consumers' 
knowledge', Advances in Consumer Research, Vol. 14, pp. 17-21.

13 Pitts, R. E., Wong, J. K. and Whalen, D. J. (1991) 'Consumers' evaluative structures in two ethical situations: A means-end approach', Journal of Business Research, Vol. 22, pp. 119-130.

14 Reynolds, T. J. and Gutman, J. (1984) 'Advertising is image management', Journal of Advertising Research, Vol. 24, pp. 27-37.

15 Gutman (1991) op. cit.

16 Walker and Olson (1991) op. cit.

17 Valette-Florence, P. and Rapacchi, B. (1991) 'Improvements in means-end chain analysis: Using graph theory and correspondence analysis', Journal of $A d$ vertising Research, Vol. 31, pp. 30-45.

18 Gutman, J. and Alden, S. D. (1985) 'Adolescents' cognitive structures of retail stores and fashion consumption: A means-end chain analysis of quality', in Jacoby, J. and Olson, J. (eds), 'Perceived quality', Lexington Books, Lexington, MA, pp. 99-114.

19 Reynolds, T. J., Gutman, J. and Fiedler, J. (1984) 'Translating knowledge of consumers' cognitive structures into the development of advertising strategic operations, A case history', Second Annual Advertising and Consumer Psychology Conference, American Psychological Association, Toronto.

20 Reynolds, T. J. and Jamieson, L. F. (1985) 'Image representations: An analytic framework, in Jacoby, J. and Olson, J. (eds) 'Perceived Quality' Lexington Books, Lexington, MA, pp. 115-138.

21 Reynolds and Gutman (1988) op. cit. 22 Reynolds, T. J. and Whitlark, D. B.
(1995) 'Applying laddering data to communications strategy and advertising practice', Journal of Advertising Research, Vol. 35, pp. 9-17.

23 Gengler, C. E. and Reynolds, T. J. (1995) 'Consumer understanding and advertising strategy: Analysis and strategic translation of laddering data', Journal of Advertising Research, Vol. 35, pp. 19-33.

24 Gengler, C. E., Klenosky, D. B. and Mulvey, M. S. (1995) 'Improving the graphic representation of means-end results', International Journal of Research in Marketing, Vol. 12, pp. 245-256.

26 Valette-Florence and Rapacchi (1991) op. cit.

27 Reynolds and Guttman (1988) op cit.

28 Valette-Florence and Rapacchi (1991) op. cit.

29 Reynolds, T. J. (1985) 'Implications for value research: A micro vs. macro perspective', Psychology and Marketing, Vol. 2, pp. 297-305.

30 Gutman (1982) op. cit.

31 Kotler, P. (1993) 'Marketing management-analysis, planning, implementation, and control', (8th ed.) Prentice-Hall International, NJ, pp. 377-378.

32 Loudon, D. L. and Bitta, A. J. della (1993) 'Consumer behavior: Concepts and Applications', (4th ed.) McGrawHill Inc., Singapore, pp. 103-107.

33 Kotler, P. and Armstrong, G. (1999) 'Principles of marketing', (9th ed.) Prentice-Hall International, NJ, pp. 143-145.

34 Hair, J. F., Jr., Anderson, R. E., Tatham, R. L. and Black, W. C. (1995) 'Multivariate data analysis', (4th ed.) 
Prentice-Hall International, NJ, pp. 420-454.

35 Stewart, D. W. and Shamdasani, P. N.
(1990) 'Focus groups: Theory and practice', Newbury Park Vol. 20, pp. $122-139$.

34 Journal of Targeting, Measurement and Analysis for Marketing Vol. 9, I, 20-35 @ C Henry Stewart Publications 0967-3237 (2000) 


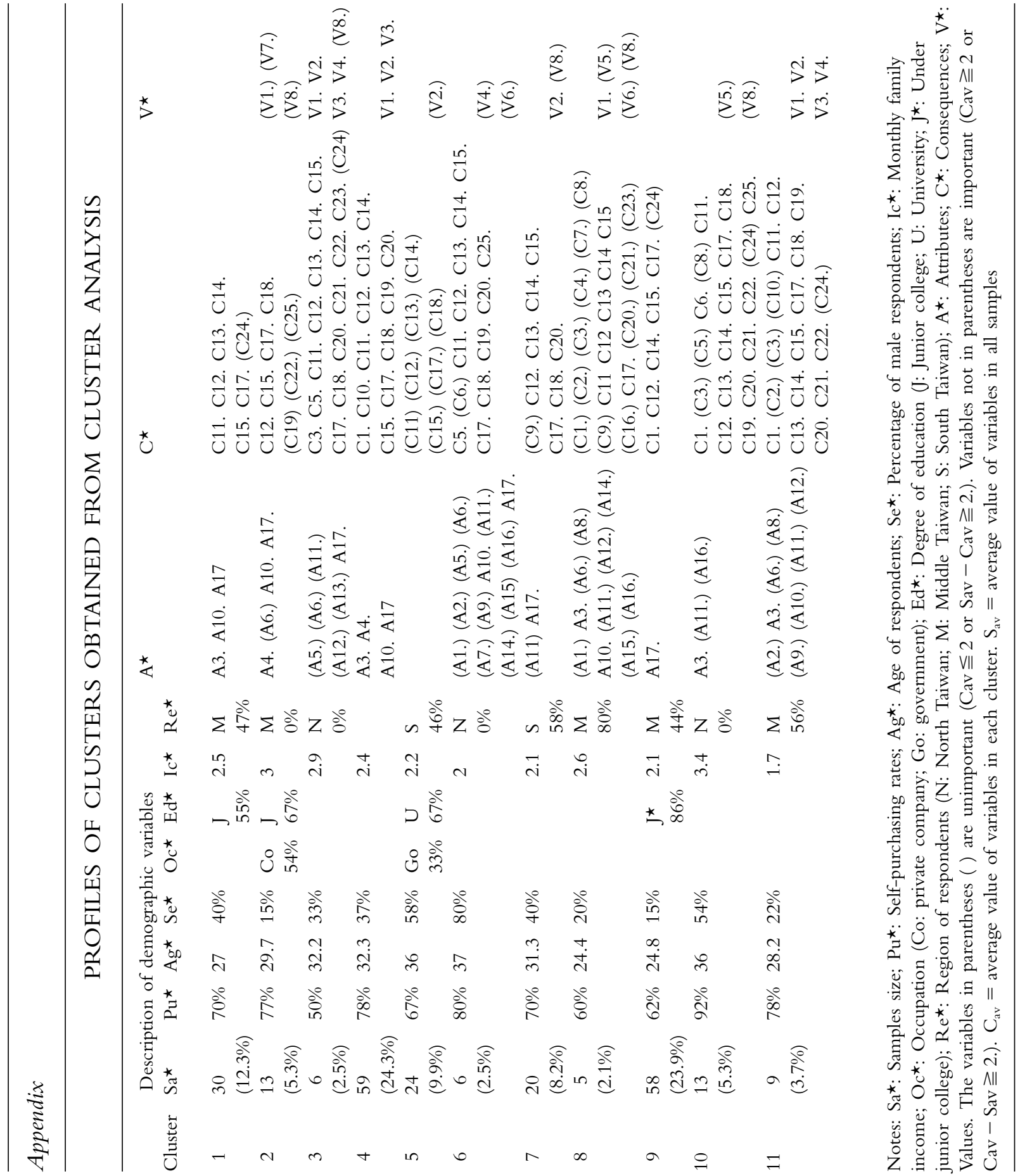

